\title{
Research on the Sales Mode of Township Home Appliances Market under the Background of New Retail---Take Suning Retail Cloud Store as an Example
}

\author{
Yang Hongyan*, Cai Shenggui, Jiang Xue, and Tong Tiantian \\ College of business administration, Guizhou University of Finance and Economics Business School, Guiyang \\ City, Guizhou Province, China
}

Keywords: New retail; Township home appliance market; Suning retail cloud store

\begin{abstract}
With the mature development of the Internet and e-commerce platform, consumers are more and more inclined to online shopping, which has a certain impact on the traditional physical industry. However, due to the weak characteristics of online shopping experience, touch ability and timeliness, how to combine offline experience and online shopping has become a problem worthy of attention. In recent years, new retail began to enter the vision of people. Specifically, new retail combines offline experience and online shopping through big data, Internet of things and artificial intelligence to create a scene shopping experience for consumers. Taking Suning retail cloud store as an example, this paper discusses the current difficulties of the Township home appliance market and explores the new sales mode under the new retail background, which provides reference for the healthy development of the blue ocean field of the Township home appliance market.
\end{abstract}

\section{Introduction}

Mobile Internet, especially e-commerce, has brought tremendous changes to people's life. Nowadays, people depend on the mobile Internet platform for clothing, food, housing and transportation, which brings great convenience to them. The development of science and technology has brought more choices to consumers, at the same time, it has also brought more discourse power to consumers, which to some extent will lead to the decline of brand loyalty of consumers. Under the wave of information technology, the development concept of traditional retail industry has also begun to change. We should focus on consumers instead of taking products as an important tool of our own marketing as before. Consumption concept of consumer has also begun to change, following the crowd is no longer their consumption orientation. Their shopping behavior more reflects individuality, interactivity and interest. As a result, the requirements for product manufacturers and distributors are strict. We are looking forward to creating a new consumption mode and realizing a new scene experience of seamless connection between consumers online and offline. Therefore, the concept of new retail, new retail mode and new retail scene emerge as the times require. Taking Suning retail cloud store as an example, this paper discusses the new sales mode of Township home appliance market, solves the problems existing in the traditional home appliance retail market, so as to provide some reference for the healthy development of Township home appliance market.

\section{The Connotation and Driving Factors of New Retail}

What is new retail? Alibaba founder Ma Yun first proposed the term "new retail". He believes that the current Internet e-commerce is very prosperous, but this trend is not immutable. The future outlet of e-commerce should return to the traditional retail, and at the same time, it should create a new retail sales mode, which is achieved by combining the Internet, physical stores and logistics. The essence of the new retail is to return to the traditional retail, but it is not exactly the same as the traditional retail. The new retail uses the thinking of "Internet plus" and combines the new technical means such as cloud computing and big data to analyze the shopping habits and preferences of consumers and form consumer portraits.[1] With the consumer demand as the core, we can provide consumers with all-round services through the integration of online drainage and offline experience, which could help to improve their shopping experience, and achieve the goal of transformation and upgrading of pure 
e-commerce platform and physical retail stores. From the economic point of view, the new retail requires enterprises and retail stores to work together to maximize the use of resources, to evolve from the supply side to the demand side, to build an efficient and agile supply chain system, to improve sales efficiency, to meet the digital needs of consumers, and to obtain the maximum profits. Technology plays an important role in the development of new retail. It is the first driving factor, including mobile Internet, big data, artificial intelligence, Internet of things and cloud computing. These new technologies are applied to the front end of new retail to guarantee the development of new retail. The second driving factor is the rise of the new generation of digital consumers. Nowadays, $90 \%$ of consumers have at least one digital contact in their shopping channels, and they are the main force of digital Internet consumption. Third, from a global perspective, the circulation efficiency of the whole Chinese market was very low before, especially compared with the Internet field, which caused a huge impact in the reverse direction, requiring us to transform the original retail to the new retail in a large area [2].

\section{The Development Dilemma of Township Home Appliances Market}

Due to the withdrawal of subsidy measures for home appliances going to the countryside and the rise of online shopping and the change of consumption structure caused by the development of Internet in the past few years, traditional rural home appliance dealers are facing severe difficulties and challenges, mainly focusing on the following two aspects:

\subsection{Lack of flexibility due to product attributes}

Because of the household appliances are durable consumer goods, market growth depends on the purchasing power and consumption demand of consumers in the final analysis. Compared with fast moving consumer goods, the period of consumer buying household appliances is longer, which is not conducive to the cash realization of dealers. That is to say, durable goods will continue to be used in the second or even the third purchase node after the first purchase node, fast moving consumer goods need to be purchased repeatedly at each purchase node. Therefore, durable goods are inelastic goods. The implementation of a certain price reduction promotion by dealers has little impact on consumers purchase behavior, which can't achieve the effect of stimulating demand in the short term. At the same time, as the government launched multiple rounds of subsidies for home appliances to the countryside in 2008, the stimulus consumption policy gradually withdrew after 2013, and the consumption overdraft stimulated by the policy also led to the downturn of the market in recent years to some extent.

\subsection{The impact of the rise of E-commerce}

In recent years, with the rapid development of computer technology and network communication technology, it has brought about the overall development of e-commerce. The Department of e-commerce and information technology of the Ministry of Commerce issued the report on China's e-commerce (2018). The data shows that in 2018, the scale of China's e-commerce transactions reached 31.63 trillion yuan, of which the online retail sales exceeded 9 trillion yuan, an increase of 23.9\% year-on-year, and the online retail sales of physical goods exceeded 7 trillion yuan, accounting for $18.4 \%$ of the total retail sales of social consumer goods. Because of the convenience, variety and price preference of online shopping, online shopping has become a more and more common way of shopping for consumers. [3]At the same time, with the post-90s and post-00s getting married and forming a small family, they are more inclined to buy everything they need in their lives online. The

online shopping behavior of these main consumers will impact the traditional offline stores to a certain extent.

\section{Research on the Sales Mode of Township Home Appliances Market under the New Retail Background}

At present, the traditional home appliance retailers, especially in the rural areas, have very simple 
business ideas. In this way, the retailers who purchase, sell and sell goods earn the price difference. However, due to the rise of major e-commerce platforms, low trust in retailers, less product stock and capital turnover, traditional home appliance retailers fall into the problems of high inventory, serious homogenization and slow product renewal. More and more home appliance retailers lose the function of sales and become the role of inventory. Under the new retail background of integrating online and offline channels, Suning retail cloud store uses offline experience and online order synchronous operation to change the single business model of traditional home appliance retailers, meet the diversified needs of consumers, and bring new vitality to the Township home appliance market.

\subsection{The combination of entity advantages and e-commerce disadvantages creates a "partnership" in which entities join}

For the retail of real household appliances, consumers can touch the products at close range through senses, touch, etc. to understand the relevant attribute information such as the material and weight of the products through touch, which is helpful to make consumers feel the quality of the products, so that they can have more confidence in product evaluation and make purchase decisions quickly. At the same time, some studies have shown that store layout, color, smell and product display can effectively stimulate consumers' emotional response, give consumers a pleasant experience, and finally stimulate consumers to buy products. Some researchers found that the emotional impact is more direct than the physical impact, and the experience marketing of stores can bring more profound associations to consumers. Before designing marketing activities, enterprises should focus on consumers and carry out activities according to the needs and preferences of target customers. In the process of experience marketing, we should pay attention to the change of consumers' attitude, pay attention to the experience feedback of consumers and relevant suggestions, and then make corresponding adjustments according to consumers' feedback. Through personal experience, consumers can form a general impression of products in terms of senses and emotional cognition. For loyal customers, experience marketing can make them have a new understanding of products. For new customers, experience and feeling can deeply understand products and their own consumption needs. It can be said that it is a kind of adhesive to enhance and familiarize products, which brings closer relationship with Consumer distance.[4] Suning retail cloud cooperates with Township home appliance retailers to realize the combination of physical advantages and online disadvantages. Suning retailers authorize their own brands to retailers and provide them with goods sources, sound logistics and distribution services to ensure the normal operation of the supply chain. In terms of store transformation, all Suning retail cloud stores use a unified brand logo, and the interior decoration is planned and designed by Suning team. First of all, it gives people a high-quality visual effect on the store image. Suning brand will take the initiative to provide free prototype display in the store, so that consumers can experience offline before they make a purchase decision, which can enhance shopping confidence. At the same time, Suning brand will take the initiative to replace products when new products are launched to meet the new needs of consumers.

\subsection{Relying on Suning online storage to solve the problems existing in the back end of the value chain of traditional retailers}

Generally, the traditional sales logic of home appliance retailers is to purchase goods from manufacturers or wholesalers first, and then customers enter the store to purchase and pay for the bill. After the payment is successful, the retailers are responsible for the shipment. When the retailers purchase goods, they need to pay in advance. The marketing logic is relatively simple, without considering other sales modes, which to some extent will cause the problem of overstock of goods and capital turnover of home appliance retailers.[5] But Suning retail cloud store is a combination of home appliance retail entity and e-commerce platform. The sales logic directly becomes that customers place an order, the store takes money and delivers goods online. Suning real retail stores only display prototypes for consumers to experience, and do not need warehouses to place goods, so home appliance retailers can directly use consumers' money to purchase goods online, and then get net profits. As online platforms have a variety of products for consumers to choose from, they can meet the diversified needs of consumers, reduce the sales risk of retailers and also reduce the 
purchase and storage costs. At present, Suning e-commerce has built its initial warehouse in 12 cities in China. According to the regional distribution, four warehouses provide national delivery services, namely, Beijing, Chengdu, Nanjing and Guangzhou. Other warehouses provide regional delivery services. The distribution network of Suning covers most parts of the country. For consumers, whether large or small goods, they can enjoy convenient and fast Suning distribution services.

\subsection{Relying on the mature logistics supply chain and after-sales service advantages of Suning e-commerce platform}

Suning enterprise is committed to building an intelligent logistics supply chain, so in addition to providing logistics services for the enterprises' own omni-channel, Suning also cooperates with suppliers, wholesalers and other partners. Suning logistics is also committed to becoming the largest supply chain infrastructure service provider in retail industry in China, providing better service support for all-round infrastructure of the supply chain. [6] Since the establishment of Suning e-commerce platform in 2012, the development has been relatively mature. Consumers can place an order on the same day, deliver it on the next day, and install it on site. These are relatively easy for Suning cloud merchants, but there is no strong logistics and distribution system for traditional home appliance retailers. At the same time, in terms of return and after-sales management, Suning promises that if there are quality problems, damaged goods, missing parts or the description of the goods is inconsistent with the website, the goods can be returned within 7 days from the next day when the customer signs for the goods, and within 15 days, the customer can submit an online application for return and replacement. Traditional home appliance retailers need to bear a large cost for the exchange of goods. For a large platform like Suning cloud business, these costs have already been included in the budget. Moreover, Suning own platform guarantee solves the original time difference between the exchange of goods and realizes the optimization and upgrading of the supply chain.

\subsection{Rely on brand advantages, increase consumer trust and influence purchase intention}

Suning, as an excellent chain retail enterprise of s home appliances, is one of the key cultivation large-scale commercial groups of the Ministry of Commerce. Since its establishment in 1990, Suning has consistently adhered to the service concept of providing consumers with high-quality products and providing consumers with comfortable experience, has strong brand appeal and accumulated a large number of loyal consumer groups. Because the brand appeal of traditional home appliance retailers is not strong, consumers can not form brand dependence in a short period of time, and it may cost a lot of cost to obtain consumers' trust. By joining the "partnership system", with the brand advantages of Suning cloud business, and at the same time, customers' experience of entering the store can fully feel the quality and performance of products, increase consumers' sense of identity for products, so as to win the trust of local consumers and affect consumers' purchase intention.

\section{Conclusion}

With the development of Internet and the maturity of e-commerce platform, it is necessary for township retailers to rely on online platform to realize the transformation of channel integration. Suning retail cloud is not only online storage for the county and town retail market, but also can reduce the risk of the retailers capital backlog. At the same time, it represents a new retail thinking under the new situation.Through the retail cloud platform, the Township home appliance stores are linked up to get through the network layout of the township retail market. Suning retail cloud will provide goods, services, logistics, management, supply chain and a series of resources for these Township outlets. As these outlets are rooted in villages and towns, densely distributed and intersected, they can bring stable customer relationships, which is conducive to the healthy development of Township home appliance retailers. At the same time, Suning retail cloud provides the corresponding customized business model according to different offline needs, helps the Township home appliance retailers to successfully transform, and to a certain extent, also drives their second entrepreneurship. In the face of the upgrading consumption mode, Township home appliance retail enterprises are also facing severe challenges. It is urgent to explore a new marketing mode. 
Suning retail cloud platform will work together with the franchised retailers to give full play to its advantages. By creating a full scene consumption experience, consumers can buy better, cheaper and higher quality goods and share the dividend of the era of smart retail. At the same time, the retail cloud store is not only limited to the household appliance industry, its business model can be copied and split, and can be expanded to areas such as home furnishings, clothing, etc., making the store more profitable.

\section{References}

[1] Zheng Mengfan, Bai Yuetong, Guo Xiuyun, Cui Lixia. Business model exploration of coffee industry in the context of new retail -- Taking Ruixing coffee as an example. Chinese market, 2019 (17): 60-61.

[2] Yang Lingya. Connotation, characteristics and types of "new retail”. Modern marketing (next ten issues), 2019 (12): 8-9.

[3] Luo Jingjie, Qian Jiayu. Research on the problems and Countermeasures of the transformation of real retail under the background of new retail. Jiangsu business theory, 2019 (12): 15-17.

[4] Chen Xi. The impact of experience marketing on consumers' purchase intention in the context of new retail. Think tank era, 2019 (24): 250-251.

[5] Zhou Wen, Li Kexin. Problems and Strategies of the development of real enterprises under the new retail mode -- Taking UNIQLO as an example. China business theory 2019 (10): 1-2 [2019-06-14].

[6] Huang Shoujia, Li Xin. Analysis of fresh food logistics problems and solutions under the background of “new retail”. Modern marketing (next ten issues), 2019 (12): 154-155. 